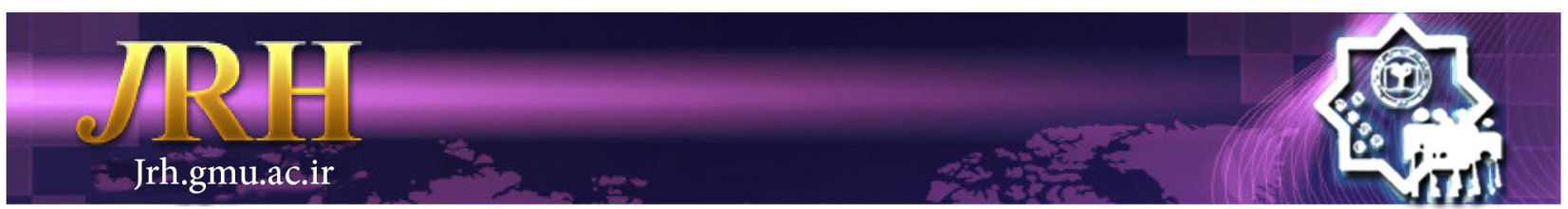

\title{
Effect and comparison of cognitive self-compassion and mindfulness on educational well-being of overweight students
}

Reza Nazeri ${ }^{1}$, Hossein Lotfabadi ${ }^{1}$, Hossein Pourshahriar ${ }^{1}$

\author{
Journal of Research \& Health \\ Social Development \& Health Promotion \\ Research Center \\ Vol. 9, No.3, May \& Jun 2019 \\ Pages: 268- 274 \\ DOI: $10.29252 / j r h .9 .3 .268$ \\ Original Article
}

1. Department of Psychology, Faculty of Psychology and Educational Sciences, Shahid Beheshti University Tehran, Iran

Correspondence to: Hossein Lotfabadi, Department of Psychology, Faculty of Psychology and Educational Sciences, Shahid Beheshti University Tehran, Iran

Email: Lotfabadih@gmail.com

Received: 28 Oct 2018

Accepted: 12 Jan 2019

How to cite this article: Nazeri R, Lotfabadi $\mathrm{H}$, Pourshahriar H. Effect and comparison of cognitive self-compassion and mindfulness on educational well-being of overweight students. J Research \& Health2019; 9(3): 268- 247

\begin{abstract}
Overweight and obesity are common issues that have increased in children and adolescents in recent years. Along the physical problems, the psychological state of these individuals has also been considered by researchers. The purpose of the present study was to investigate the effect of cognitive self-compassion and mindfulness on the educational well-being of overweight adolescent students. The research method was a pretest-posttest with a control group. The participants consisted of 60 male overweight students (each group, 20) who were selected through a purposeful sampling and were assigned to two experimental and one control groups. Two questionnaires including educational engagement scale and the pleasure of physical activity scale were used to collect data. One group received cognitive self-compassion and the other group received mindfulness training and the control group did not receive any training. According to the results that self-compassion training and mindfulness significantly increased academic engagement and enjoyment of physical activity. The findings showed that there was no difference between the two methods of increasing the pleasure of physical activity, but mindfulness training had a greater effect on increasing academic engagement. Overall, the results showed that these two methods could significantly increase the educational well-being of overweight students.
\end{abstract}

Keywords: Adolescent Well-being, Compassion, Mindfulness, Overweight, Students

\section{Introduction}

Today, obesity and overweight in many developing countries have increased dramatically and it is the cause of many illnesses [1]. In Asian countries like Iran, obesity has been reported to be over 23\% [2]. Estimates by the Tehran Lipid and Glucose Institute show that the in women prevalence of obesity was increased from $32.7 \%$ to $40.30 \%$ and in men, it was increased from $16.5 \%$ to $20.8 \%$ between 1999 and 2002 [3]. Obesity and overweight are highly prevalent in the countries of the world, especially in Iran.
The results of studies conducted on student societies indicate that obesity in school years is associated with numerous health problems [4] and that obesity threatens many students and has a significant impact on student performance [5].

However, accurate information about causes of obesity is not available, but the results show that the environmental conditions are affected in obesity and that a child with obese father or mother has a $50 \%$ chance of 
being overweight and if both parents are obese, this chance will be $80 \%$. Therefore, genetic factors play a significant role in this disorder [6]. The studies in Australia, Canada, England, and South Korea show that there is a strong correlation between obesity and education [7] and obesity and overweight affected on various aspects of life, including academic achievements and social skills of children. The obese children deprived of their friends and relatives, have poor social skills and are at high risk for psychosocial problems. Poor social skills and social problems those are associated with obesity and overweight result in poor educational performance and ultimately poor educational self-concept in obese and overweight students $[8,9]$. The findings indicate that academic achievement is positively correlated with physical fitness. Obese students are less progressively educated due to lack of agility and are one of the biggest problems of obesity, its impact on academic achievement and academic well-being of students [10].

Educational well-being has recently been raised in educational psychology. Gutman and Vorhaus [11] consider school wellbeing as the enjoyment of physical activity in school (that students state that they like school and enjoy physical and bodily activity) and being engaged in school (i.e., do students are motivated by homework and schoolwork) and academic satisfaction (proper interaction with school officials, interest in studying). Vignoles and Meschi [12] assessed the attitude of students about the school, which was about enjoying school and engaging in school activities. The findings showed that students who had a positive attitude towards school at age 14 had the highest academic achievement at age 16; the students with the highest educational achievement at age 11 had the most positive attitude toward school by age 16 .

The findings were inconsistent in regard to the enjoyment of school activities and academic achievement and attainment of higher grades in elementary schools so that communication with teachers and academic achievement in elementary school in the following years was unrelated [13]. Gutman, Brown, Akerman, and Obolenskaya [14] argued that the school's wellbeing was significantly lower in boys than in girls. They reported that the level of the school's wellbeing is decreasing with increasing educational level and this decrease is higher among boys. As discussed, educational well-being has two components, one of which is educational engagement. Educational engagement is a structure that was first introduced to understand and explain academic failure and was considered as the foundation for reformist efforts in the field of education. One of the most important indicators of the quality of education and academic progress is educational engagement. Educational engagement includes behavioral, cognitive, and motivational components [15]. The behavioral component of academic engagement refers to visible educational behaviors such as effort and sustainability when faced with problems during homework assignments. The cognitive component of the educational engagement is metacognitive strategies when studying the content of the lesson and the motivational component includes the internal interest in the subject and the content of the lesson, value, and importance to them, and the existence of positive affection and lack of frustration, anxiety, and anger during the coursework [16]. In addition to the educational engagement, the pleasure of physical activity is one of the important concepts in the education of students, especially overweight students. Findings suggest that poorer physical activity is associated with negative emotions [17]. Undoubtedly, students enjoy the most in sport and physical activity, and the school should apply the conditions for this activity to increase the psychological well-being of the students.

Researchers suggest that increasing physical activity was correlated with physical and psychological health and preventing many diseases, including obesity. So that, an increase in physical activity in a child's life, predicting the level of activity and increasing physical 
activity in adulthood [18]. Undoubtedly, obesity and overweight affected in students' physical activity as a primary factor.

Mindfulness is one of the most influential variables in the field of education. The mindfulness is an activity that focuses on the present moment, not past and future, which concentrate all the attention of the individual on the present moment [19]. Mindfulness simply focuses on the ongoing activity, while other stimuli that may distract the attention of the individual are ignored. This method is a kind of meditation or relaxation technique that by concentrating the thoughts, emotions and feelings of an individual on the moment increases the self-awareness of an individual about his experience [20]. The practice of mindfulness is historically rooted in Buddhism, and has spread from east Asia to other parts of the world in recent years [21].

A number of studies have showed that mindfulness can help the emotional regulation and mental well-being of children and adolescents [22]. Studies have also revealed that mindfulness can affect students' behavior and their level of anxiety [23,24]. Mindfulness has the potential to set students' behaviors and emotions by relaxing their minds and concentrating their attention on the moment.

Self-compassion is another variable that has received significant research attention in recent years. Researches have shown that selfcompassion affects the mental well-being of individuals [25]. Based on the concept of selfcompassion, a pleasant encounter with negative emotions instead of resisting or suppressing them can result in positive emotions and is associated with psychological abilities [26]. Also, self-compassion has similar effects on adolescents [27]. Neff considers self-compassion as an encounter with personal suffering and experiences a sense of care and kindness toward oneself, having a non-judgmental perception and attitude toward his disability and inadequacy, and understanding that difficult experiences are part of shared experiences all human beings. He sees the self-compassion structure with three interconnected components: self-kindness, common humanity, and mindfulness. Other scholars have emphasized that self-compassion involves a fundamental link with others that are related to the mental well-being of people [28].

Accordingly, today one of the effective methods in the field of physical activity and nutritional behaviors of students at the schools is self-compassion and mindfulness training. Despite extensive foreign research in this regard, studies have shown that a few studies have been conducted in the field of educational well-being in Iran. Therefore, the purpose of this study was to investigate the effect of cognitive self-compassion and mindfulness training on student's educational well-being.

\section{Method}

The present research is semi-experimental research with pretest and posttest design and control group. The statistical population of the study included all high school students in Tehran during the 2015-2016 academic year, that were overweight based on the index of Body Mass Index (BMI). In this study, purposive sampling method was used for the sampling and out of 32 schools based on their willingness to cooperate in the study, 60 boy students were selected as a sample on the basis of criteria I) a body mass index greater than 25 II) had an educational well-being problem that was identified by using the educational wellbeing questionnaire; III) they had a willingness and informed consent to participate in the research. In the first stage, the subjects were randomly divided into two experimental and one control groups. Subsequently, the experimental groups received self-compassion and mindfulness training, while the control group did not receive any training. Before and after 8 sessions of training, the educational engagement questionnaire and the pleasure from the physical activity scale were performed in the experimental and control groups.

In this study, the pleasure of physical activity and educational engagement questionnaire were used to assess educational well-being 
two questionnaires. The educational engagement scale has been developed by Fredricks and Blumenfeld [15] in the form of 15 items that has three motivational, behavioral and cognitive components. This scale has five degrees Likert response and its scores range is between 15 and 75. The reliability of this questionnaire has been reported in the main study 0.88 and its validity has been confirmed by exploratory factor analysis. Talebi et al. [29] in an Iranian sample confirmed the psychometric properties of this scale using confirmatory factor analysis $(\mathrm{RMSEA}=0.034)$ and the Cronbach's alpha's cognitive subscale was 0.74 , behavioral 0.86 , and motivational 0.79 . In this research, Cronbach's alpha method was used to assess reliability. Cronbach's alpha was obtained for cognitive, behavioral and motivation subscales $0.75,0.84$ and 0.88 respectively.

The pleasure of physical activity scale has 18 items that were made by Kendzierski and DeCarlo to assess the enjoyment of physical activity [30]. It has seven degrees Likert response scale and the range of scores is between 18 and
126. The designers of this questionnaire have reported the reliability of this questionnaire using the Cronbach's alpha method equal to 0.93 and confirmed its validity by exploratory factor analysis. In this research, Cronbach's alpha method was used to assess reliability. Cronbach's alpha was obtained at 0.78 .

Covariance analysis was used to test the research hypotheses by using SPSS-22 software version at 0.05 significant level.

Covariance analysis was analyzed to investigate the difference between the pleasure of physical activity scores of overweight students in posttest of three groups with control and the pretest scores. KolmogorovSmirnov test (K-S) was used to ensure the normality of the data.

\section{Results}

The mean scores of academic engagement and pleasure of physical activity in mindfulness, self-compassion and control group were presented in pretest and posttest in Table 1.

Table 1 Descriptive statistics of research variables in pretest and posttest

\begin{tabular}{lccccc}
\hline \multirow{2}{*}{ Variable } & \multirow{2}{*}{ Group } & \multicolumn{2}{c}{ Pretest } & \multicolumn{2}{c}{ Posttest } \\
\cline { 3 - 6 } & & Mean & SD & Mean & SD \\
\hline \multirow{2}{*}{ Educational engagement } & Self-compassion & 52.88 & 5.46 & 59.88 & 2.80 \\
& Control & 53.47 & 5.70 & 55.47 & 5.13 \\
& Mindfulness & 67.35 & 7.367 & 92.82 & 7.09 \\
Pleasure of physical & Self-compassion & 68.35 & 10.09 & 91.28 & 6.56 \\
activity & Control & 69.64 & 9.12 & 74.23 & 8.70 \\
\hline
\end{tabular}

The results of the Kolmogorov-Smirnov test showed data distribution was normal. Levene's test also showed that homogeneity of variance was confirmed. The results of Table 2 show that the difference between the three groups in the variable of pleasure of physical activity is significant. Therefore, the Bonferroni test was used to find out the difference between the means.

The results of the Bonferroni test show that there is a significant difference between the mindfulness and self-compassion groups with the control group in the posttest, but there wasn't a significant difference between the two groups of self-compassion and mindfulness in the pleasure of physical activity (Table 3 ).

Table 2 One-way covariance analysis on mean of posttest scores of pleasure of physical activity

\begin{tabular}{lcccccc}
\hline Variable & SS & DF & MS & F & Effect size & Sig. \\
\hline Group & 4585.44 & 2 & 3274.22 & & & \\
Error & 2724.98 & 57 & 80.47 & 28.26 & 0.62 & 0.001 \\
\hline
\end{tabular}


Table 3 Bonferroni test to compare the scores of groups in the variable of pleasure of physical activity

\begin{tabular}{llccc}
\hline Variable & Comparison & $\begin{array}{c}\text { Mean } \\
\text { differences }\end{array}$ & SD & Sig. \\
\hline \multirow{2}{*}{$\begin{array}{l}\text { Pleasure of } \\
\text { physical activity }\end{array}$} & Mindfulness-self compassion & 1.54 & 2.91 & 0.79 \\
& Mindfulness-control & 18.59 & 2.84 & 0.01 \\
& Self-compassion-control & 17.05 & 2.66 & 0.01 \\
\hline
\end{tabular}

The results of Table 4 showed that the difference between the three groups in the variable of educational engagement is significant. Therefore, the Bonferroni test was used to find out the difference between the means.

The results of the Bonferroni test show that there is a significant difference between the mindfulness and self-compassion groups with the control group in the posttest. There is also a significant difference between the two groups of self-compassion and mindfulness in this variable favor of the mindfulness group (Table 5).

Table 4 One-way covariance analysis on the mean scores of posttest

\begin{tabular}{ccccccc}
\hline Variable & SS & DF & MS & F & Effect size & Sig. \\
\hline Group & 1591.30 & 2 & 795.65 & & & \\
Error & 1017.91 & 57 & 17.85 & & 0.61 & 0.001 \\
\hline
\end{tabular}

Table 5 Bonferroni test result for comparing the scores of the groups

\begin{tabular}{llccc}
\hline Variable & Comparison & $\begin{array}{c}\text { Mean } \\
\text { differences }\end{array}$ & SD & Sig. \\
\hline \multirow{2}{*}{$\begin{array}{l}\text { Educational } \\
\text { engagement }\end{array}$} & Mindfulness-self compassion & 8.17 & 1.38 & 0.01 \\
& Mindfulness-control & 12.58 & 2.84 & 0.01 \\
& Self-compassion-control & 4.41 & 2.66 & 0.01 \\
\hline
\end{tabular}

\section{Discussion}

Results of the current research indicated that mindfulness training can increase the pleasure of physical activity and academic engagement in overweight students. The results are consistent with the research by Felver et al. [31] Cox et al. [32] and Singh et al. [33]. To explain this finding, it can be argued that mindfulness can play an important role in increasing students' academic satisfaction due to their significant role in increasing psychological well-being in obese and overweight people. Cox et al. [32] found that mindfulness training had a significant effect on self-concept and health. Mindfulness training can improve psychological performance and reduce the negative effects of stress on students. This causes that mindfulness plays an important role in the academic engagement of students. Mindfulness, especially in terms of the effect on increasing student mood, can regulate blood pressure and cortisol levels and increase the level of well-being [33].
Also, self-compassion training increased the pleasure of physical activity and academic engagement. The results are consistent with Cox et al. [32], Kelly et al. [33] and Wasylkiw et al. [34]. The more self-compassion people are less likely to develop nutritional disorders. Self-compassion by increasing physical activity can decrease the number of nutritional disorders [35]. On the other hand, selfcompassion can be a supportive variable such as the development of a healthy self-concept and the reduction of concern in this field, to reduce nutritional disorders [36]. Ferreira et al. [37] found that high self-compassion was correlated with the low amount of weight loss in women with eating disorders. By controlling the body mass index and self-confidence, self-compassion was inversely related to overeating. Therefore, these changes that were created by self-compassion can adjust nutritional issues and may increase physical activity and pleasure of it. 
Therefore, it can be argued that someone who is overweight, when he/she is injured, failed, or feels incapacitated for the body, applies self-compassion and understands himself/ herself instead of ignoring the suffering or criticizes self. Also, the results indicated that the mindfulness training compare to self-compassion had a more important role in increasing academic engagement. The findings of this study are consistent with the results of Cox et al. [32], Kelly et al. [34] and Wasylkiw et al. [35]. One of the possible reasons for more effectiveness of Mindfulness training is the cognitive and emotional content of mindfulness training compared to the purely emotional nature of self-compassion training. The cognitive and emotional nature of mindfulness training adds more resources to increase academic engagement and change in the positive direction.

It should be noted that along with the results obtained, there are some limitations that should be taken into account in the generalizability of the findings. The limited sample of high school male students and the use of self-report questionnaires were the most important of these limitations.

\section{Conclusion}

Overall, the results showed that mindfulness and self-compassion training can significantly improve the educational well-being of overweight students, and can be used as effective strategies for increasing student's educational well-being.

\section{Acknowledgments}

The authors thank all students who participated in this research.

\section{Contribution}

The idea and design of the study: HL

Collecting and analyzing data: RN

Writing and Preparing the Article: HP

\section{Conflict of Interest}

"The authors declare that they have no competing interests."

\section{Funding}

The author (s) received no financial support for the research, authorship and/or publication of this article.

\section{References}

1- Kopelman PG. Causes and consequences of obesity. Med Int 1994; 22: 385-8.

2- Esteghamati A, Meysamie A, Khalilzadeh O, et al. Third national surveillance of risk factors of non-communicable diseases (SuRFNCD-2007) in Iran: methods and results on prevalence of diabetes, hypertension, obesity, central obesity, and dyslipidemia. BMC Public Health2009; 9(1): 167.

3-Azizi F, Azadbakht L, Mirmiran P. Trends in overweight, obesity and central fat accumulation among Tehranian adults between 1998-1999 and 2001-2002: Tehran lipid and glucose study. Ann Nutr Metab2005; 49(1): 3-8.

4- Mulvaney SA, Kaemingk KL, Goodwin JL, Quan SF. Parent-rated behavior problems associated with overweight before and after controlling for sleep disordered breathing. BMC Pediatr2006; 6(1): 34 .

5- Gunter KB, Nader PA, John DH. Physical activity levels and obesity status of oregon rural elementary school children. Prev Med Rep2015; 2: 478-82.

6- Rapuano KM, Zieselman AL, Kelley WM, Sargent JD, Heatherton TF, Gilbert-Diamond D. Genetic risk for obesity predicts nucleus accumbens size and responsivity to real-world food cues. Proc Natl Acad Sci USA2017; 114(1): 160-5.

7- Devaux M, Sassi F, Church J, Cecchini M, Borgonovi F. Exploring the relationship between education and obesity. OECD Journal: Economic Studies2011; 2011(1): 121-59. 8- Kantomaa MT, Stamatakis E, Kankaanpää A, et al. Physical activity and obesity mediate the association between childhood motor function and adolescents' academic achievement. Proc Natl Acad Sci USA2013;110(5): 1917-22.

9- Pugh SJ, Hutcheon JA, Richardson GA, et al. Gestational weight gain, prepregnancy body mass index and offspring attention-deficit hyperactivity disorder symptoms and behaviour at age 10. BJOG2016; 123(13): 2094-103.

10- Datar A, Sturm R. Childhood overweight and elementary school outcomes. Int J Obes2006; 30(9): 1449-60.

11- Gutman LM, Vorhaus J. The impact of pupil behaviour and wellbeing on educational outcomes. London: Institute of Education, University of London, Childhood Wellbeing Research Centre; 2012.

12- Vignoles A, Meschi E. The determinants of noncognitive and cognitive schooling outcomes. Report to the department of children, schools and families. London: 
Centre for the economics of education (NJ1); 2010.

13- Gutman L, Feinstein L. Children's well-being in primary school: Pupil and school effects (Wider benefits of learning research report No. 25). London: Centre for research on the wider Benefits of learning, Institute of education, university of London; 2008.

14- Gutman L, Brown J, Akerman R, Obolenskaya P. Change in wellbeing from childhood to adolescence: Risk and resilience (Wider benefits of learning research report No. 34). London: Centre for research on the wider benefits of learning, institute of education, university of London; 2010.

15- Fredricks JA, Blumenfeld PC, Paris AH. School engagement: potential of the concept, state of the evidence. Rev Educ Res2004; 76(1): 59-109.

16- Linnenbrink EA, Pintrich PR. The role of selfefficacy beliefs instudent engagement and learning in the classroom. Read Writ Q2003; 19(2): 119-37.

17- Mullen SP, Olson EA, Phillips SM, et al. Measuring enjoyment of physical activity in older adults: invariance of the physical activity enjoyment scale (paces) across groups and time. Int J Behav Nutr Phys Act2011; 8(1): 103. 18- Telama R, Yang X, Viikari J, Välimäki I, Wanne O, Raitakari O. Physical activity from childhood to adulthood: a 21-year tracking study. Am J Prev Med2005; 28(3): 267-73.

19- Hooker KEF, Fodor IE. Teaching mindfulness to children. Gestalt Rev2008; 12(1): 75-91.

20- Horan R. The neuropsychological connection between creativity and meditation. Creat Res J2009; 21(2-3): 199-222.

21- Ostafin BD, Kassman KT. Stepping out of history: Mindfulness improves insight problem solving. Conscious Cogn2012; 21(2): 1031-6.

22- Durlak JA, Weissberg RP, Dymnicki AB, Taylor RD, Schellinger KB. The impact of enhancing students' social and emotional learning: A meta-analysis of school-based universal interventions. Child Dev2011; 82(1): 405-32.

23- Black DS, Fernando R. Mindfulness training and classroom behavior among lower-income and ethnic minority elementary school children. $J$ Child Fam Stud2014; 23(7): 1242-6.

24- Semple RJ, Lee J, Rosa D, Miller LF. A randomized trial of mindfulness-based cognitive therapy for children: Promoting mindful attention to enhance socialemotional resiliency in children. J Child Fam Stud2010; 19(2): 218-29.

25- MacBeth A, Gumley A. Exploring compassion: A metaanalysis of the association between self-compassion and psychopathology. Clin Psychol Rev2012; 32(6): 545-52.
26- Neff KD, Dahm KA. Self-compassion: what it is, what it does, and how it relates to mindfulness. In: Ostafin B, Robinson M, Meier B, eds. Handbook of mindfulness and self-regulation. New York: Springer NY; 2015. pp: 121-37.

27- Neff KD. The development and validation of a scale to measure self-compassion. Self-Identity2003; 2(3): 223-50.

28- Baer RA. Self-compassion as a mechanism of change in mindfulness-and acceptance-based treatments. Assessing mindfulness and acceptance processes in clients: Illuminating the theory and practice of change. Oakland: New harbinger publications; 2010.

29- Talebi S, Zare H, Rastegar A, Hoseinpoor A. Factor structure of Friedrich's educational engagement scale (cognitive, behavioral, and motivational). Research in Educational Systems2014; 8(24): 1-16.

30- Kendzierski D, DeCarlo KJ. Physical activity enjoyment scale: Two validation studies. J Sport Exerc Psychol1991; 13(1): 50-64.

31- Felver JC, Celis-de Hoyos CE, Tezanos K, Singh NN. A systematic review of mindfulnessbased interventions for youth in school settings. Mindfulness 2016; 7(1): 34-45.

32- Cox AE, Ullrich-French S, Cole AN, D'HondtTaylor M. The role of state mindfulness during yoga in predicting self-objectification and reasons for exercise. Psychol Sport Exerc2016; 22: 321-7.

33- Singh NN, Lancioni GE, Winton AS, Karazsia BT, Singh J. Mindfulness training for teachers changes the behavior of their preschool students. Res Hum Dev2013; 10(3): 211-33.

34- Kelly AC, Vimalakanthan K, Miller KE. Selfcompassion moderates the relationship between body mass index and both eating disorder pathology and body image flexibility. Body Image2014; 11(4): 446-53.

35- Wasylkiw L, MacKinnon AL, MacLellan AM. Exploring the link between self-compassion and body image in university women. Body Image2012; 9(2): 236-45.

36- Reis NA, Kowalski KC, Ferguson LJ, Sabiston CM, Sedgwick WA, Crocker PR. Self-compassion and women athletes' responses to emotionally difficult sport situations: An evaluation of a brief induction. Psychol Sport Exerc2015; 16(3): 18-25.

37- Ferreira C, Pinto-Gouveia J, Duarte C. Selfcompassion in the face of shame and body image dissatisfaction: Implications for eating disorders. Eat Behav2013; 14(2): 207-10.

Copyright $\bigcirc 2016$ ASP Ins. This open-access article is published under the terms of the Creative Commons Attribution-NonCommercial 4.0 International License which permits Share (copy and redistribute the material in any medium or format) and Adapt (remix, transform, and build upon the material) under the Attribution-NonCommercial terms. 